\title{
Blastic Plasmacytoid Dendritic Cell Neoplasm
}

National Cancer Institute

\section{Source}

National Cancer Institute. Blastic Plasmacytoid Dendritic Cell Neoplasm. NCI Thesaurus.

Code $C 7203$.

A clinically aggressive neoplasm derived from the precursors of plasmacytoid dendritic cells (also called professional type I interferon-producing cells or plasmacytoid monocytes), with a high frequency of cutaneous and bone marrow involvement and leukemic dissemination. (WHO 2017) 